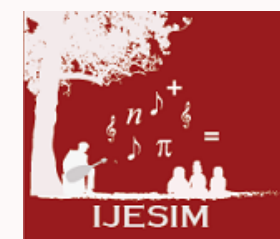

International Journal of Educational Studies in Mathematics

ISSN: 2148 - 5984

wWw.ijesim.com

\title{
An Investigation of Pre-Services Mathematics Teachers' Performances on Systems of Linear Equations within the Context of Self-Efficacy Levels
}

\author{
Ali Delice1, Emin Aydın, Deniz Kardeş Birinci² \\ ${ }^{1}$ Marmara University, Ataturk Education Faculty, Department of Secondary Mathematics Education, Istanbul, TURKEY \\ ${ }^{2}$ Fatih University, Education Faculty, Department of Primary Mathematics Education, Istanbul, TURKEY
}

ABSTRACT

\begin{abstract}
The aim of this research is to investigate preservice mathematics teachers' performances on systems of linear equations within the context of self-efficacy on systems of linear equations. The research uses a case study methodology which follows from the qualitative paradigm. 42 second year pupils from the department of primary mathematics education in 2009-2010 academic year were chosen for the study by using the convenience sampling strategy. Performance Test of Systems of Linear Equations was used to assess of the preservice mathematics teachers' performances on solving systems of linear equations and Systems of Linear Equations Self-efficacy Test $(m=n, m \neq n)$ was developed and used to determine the levels of efficacy. In the analysis of the quantitative qualitative and data, inferential and descriptive statistics were used respectively. While the majority of preservice mathematics teachers showed medium-level performance, more than half of the participants had high-levels of self-efficacy. The presence of a significant positive medium level correlation between performance and self-efficacy is an indicator of the fact that self-efficacy affects performance.
\end{abstract}

Keywords:

Linear algebra, Systems of linear equations, Self-efficacy, Teacher education

(C) 2014 IJESIM. All rights reserved

Article History:

Received 22.11.2014 Received in revised form 27.11.2014 Accepted 30.11.2014 Available online 02.12.2014

\section{Extended Summary}

Linear algebra is a mathematical domain encountered by students in all levels of education from primary school, not only at the university level. The attainment related to the solution of linear equations with two unknown involved in primary school mathematics curriculum can be stated as the starting point of the systems of linear equation.

Learning and teaching of the systems of linear equations have been the focus of many studies (Kardeş, 2010; Trigueros, Oktaç and Manzanero, 2007; Cutz, 2005, cited in Oktaç, 2008; Harel and Tall, 1989). The aim of this research is to investigate preservice mathematics teachers' performances on systems of linear equations within the context of self-efficacy theory.

The research uses a case study methodology which follows a qualitative paradigm. 42 second year pupils of the department of primary math education participated in the study, Participants were chosen by using the convenience sampling strategy. Qualitative and quantitative methods were used together to collect the relevant data. Performance Test of Systems of Linear Equations was used to assess of the preservice

\footnotetext{
${ }^{1}$ Corresponding author's address: Marmara University, Ataturk Education Faculty, Department of Secondary Mathematics Education, Istanbul, TURKEY

Telephone: +905057993324

Fax: 02163473366

e-mail: alidelice@marmara.edu.tr

http://dx.doi.org/10.17278/ijesim.2014.02.002
} 
mathematics teachers' performances on solving systems of linear equations. The test consists of 13 questions which were selected by using various criteria relevant to the topic. In addition, to determine the level of efficacy levels Systems of Linear Equations Self-efficacy Test $(m=n, m \neq n)$ was developed, in which $m$ denotes the number of equations and $n$ shows the number of variables. For the situation $m=n$, which consists of 17 items, the coefficient of alpha is 0.86 , for the $m \neq n$ one, which consists of 12 items, Cronbach-alpha is 0.83. In the analysis of the quantitative data, predictive statistics were used; in the analysis of the qualitative data, descriptive statistics were used.

When preservice mathematics teachers' overall performance levels on a systems of linear equations are investigated, findings indicated that the majority of participants showed medium-level performance $(76 \%)$. High-level $(17 \%)$ and low-level $(7 \%)$ performance were less frequent. Results on preservice mathematics teachers' overall self-efficacy levels on the systems of linear equations showed that 59,52's\% had high-level, 33.33 's\% had medium-level, and 9,52's\% had low-level self-efficacy. Very high-level and very low-level selfefficacy levels were not observed and that more than half of the participants had high-level self-efficacy levels.

In the investigation of the relationship between preservice mathematics teachers' performances and their self-efficacy levels, both correlational and descriptive statistics were used to obtain a brighter picture. A significant positive correlation was found between preservice mathematics teachers' performances and their self-efficacy levels $(\mathrm{r}=0.46 ; \mathrm{p}<.05)$. As for the descriptive comparisons between different levels of two variables, it was observed that $20 \%$ of participants had high level self-efficacy and high level performance, $24 \%$ of participants had medium level self-efficacy and medium level performance, $4 \%$ of participants had low level self-efficacy and low level performance.

The performance test and self-efficacy scale are investigated in terms of subscales, It can be stated that participants' performances and self-efficacy in solving systems of linear equations by using ranks $(m=n)$, inverse matrices and determinants showed parallel results. Preservice mathematics teachers who see themselves competent in making row operations $(m \neq n)$ and algebraic interpretations showed medium level performance; participants who see themselves mediocre in making correct geometric interpretations showed low level performance in solving a system in the performance test. 


\title{
Matematik Öğretmen Adaylarının Lineer Denklem Sistemleri Çözüm Performanslarının Öz-Yeterlik Alg1 Düzeyleri Bağlamında İncelenmesi
}

\author{
Ali Delice', Emin Aydın1, Deniz Kardeş Birinci² \\ ${ }^{1}$ Marmara Üniversitesi, Atatürk Ĕ̆itim Fakültesi, Ortaöğretim Matematik Öğretmenliği, İstanbul, TÜRKIYYE \\ ${ }^{2}$ Fatih Üniversitesi, Ĕ̆itim Fakültesi, İlköğretim Matematik Öğretmenliği, İstanbul, TüRKİYE
}

\begin{abstract}
Bu araştırmada, matematik öğretmen adaylarının lineer denklem sistemleri konusunda sergiledikleri performanslarının lineer denklem sistemleri öz-yeterlik algı düzeyleri bağlamında incelenmesi amaçlanmaktadır. Ölçeğin konu bazında geliştirilerek performansla ilişkisinin araştırılması çalışmanın özgünlüğünü ortaya koymaktadır. Özel durum deseninin benimsendiği araştırmada katılımcılar, olasılıksız örnekleme yöntemlerinden amaçlı örnekleme tekniği ile belirlenmiş olup 2009-2010 eğitim öğretim yılında, bir devlet üniversitesi eğitim fakültesi ilköğretim matematik eğitimi lisans programına kayıtlı 42 lineer cebir öğrencisinden oluşmaktadır. Çalışmada veri toplama araçları olarak, araştırmacılar tarafından geçerlik ve güvenirlik çalışmaları yapılarak geliştirilen Lineer Denklem Sistemleri Öz-yeterlik Algısı Ölçeği ve Lineer Denklem Sistemleri Performans Testi kullanılmıştır. Elde edilen nicel veriler kestirimsel, nitel veriler ise betimsel istatistik kullanılarak analiz edilmiştir. Araştırmada, öğretmen adaylarının lineer denklem sistemleri konusunda orta düzeyde performans sergilerken öz-yeterlik algılarının yüksek düzeyde olduğu görülmüştür. Sergilenen performans ile öz-yeterlik algı düzeyleri arasındaki pozitif yönde orta düzeyde anlamlı ilişkinin varlığı özyeterlik algısının performansı etkilediğinin bir göstergesidir.
\end{abstract}

Anahtar Kelimeler:

Lineer denklem sistemleri, performans, öz-yeterlik algısı, öğretmen eğitimi

(C) 2014 IJESIM. Tüm hakları saklıdır.

Makale Tarihçesi:

Alındı 22.11.2014 Düzeltilmiş hali alındı 27.11.2014 Kabul edildi 30.11.2014 Çevrimiçi yayınlandı 02.12.2014

\section{Giriş}

Yirminci yüzyılın son on yılında lineer cebir alanında yapılan sessiz reform hareketleri, bu alanın önemine yönelik vurgu yapılmasını sağlamıştır. Bu yıllarda kurulan Lineer Cebir Öğretim Programı Çalışma Grubu (Linear Algebra Curriculum Study Group, LACSG), lineer cebir öğretim programının birçok okulda öğrencilerin ihtiyaçlarına hizmet etmediği endişesiyle, yeni bir öğretim programı önermeyi amaçlamıştır. Bu öğretim programında, lineer cebir ders planı ve sunumunun öğrencilerin ihtiyaçlarını yanıtlaması; matematik bölümlerinde lineer cebir dersinin matris temelli öğretiminin yapılması; öğrencilerin ilgi alanlarının da dikkate alınarak lineer cebir derslerinde teknoloji kullanımını desteklenmesi şeklinde bazı öneriler sunulmuştur (Carlson, 1993).

Lineer cebir sadece üniversite düzeyinde değil, ortaokuldan itibaren her öğrenim düzeyinde öğrencilerin karşılaştı̆̆ı matematiksel bir alandır. Ortaokul matematik öğretim programında iki bilinmeyenli denklem sistemlerinin çözümü ile ilgili yer alan kazanımın lineer denklem sistemleri konusunun başlangıç noktası olduğu ifade edilebilir. Lineer denklem sistemlerinin (LDS) öğrenimi ve öğretimi birçok araştırmanın odak noktası olmuştur (Kardeş, 2010; Trigueros, Oktaç ve Manzanero, 2007; Cutz, 2005, akt. Oktaç, 2008; Harel ve Tall, 1989). Öğrencilerin var olan bilgilerinin üzerine yenilerini nasıl inşa ettiklerini genelleme kavramı bağlamında ele alan Harel ve Tall (1989) matematiksel alan olarak lineer denklem sistemleri konusunu temel almışlardır. Araştırmalarında işlemsel anlamaya sahip olan öğrencilerin "denklemin her iki tarafına da aynı işlemleri yap, x'li ifadeleri bir tarafta topla, sayıları diğer tarafta topla, taraf değişirse işaret de değişir, benzer terimleri bir tarafa topla" gibi kurallar kullandıklarını ve kural listelerine yenilerini eklediklerini, ilişkisel anlamaya sahip olan öğrencilerin denklem çözümleriyle ilgili şemalarını zenginleştirip genişlettiklerini belirtmektedirler. APOS (Action, Process, Object, Schema) teorik çerçeveli odaklı öğretim yapılan lineer cebir dersinde, öğrencilerin lineer denklem sistemleri konusundaki

Sorumlu yazarın adresi: Marmara Üniversitesi, Atatürk Eğitim Fakültesi, Ortaöğretim Matematik Öğretmenliği ABD, Kadıköy, İstanbul.

Telefon: 05057993324

Faks: 02163473366

e-posta: alidelice@marmara.edu.t

http://dx.doi.org/10.17278/ijesim.2014.02.002 
performanslarının kendilerinin değişken ile ilgili şemalarına bağlı olduğunu ifade eden Trigueros, Oktaç ve Manzanero (2007) bu durumun konunun anlamlandırılması için ön-koşul olarak sayılabileceğini eklemektedirler. Lineer denklem sistemleri konusunu kullanılan grafik temsili bağlamında ele alan Cutz (2005, akt. Oktaç, 2008) öğrencilerin genellikle üç denklemden oluşan iki bilinmeyenli sistemlerin geometrik olarak temsiline alışkın olmadıkları sonucuna varmıştır. Häggström (2006) lineer denklem sistemleri konusunun öğretiminde işleniş biçiminin öğrencilerin öğrenmelerine etkisini üç farklı sınıf ortamında araştırmış ve öğrencilerin lineer denklem sistemleri problem çözümünü öğrenmelerinden işleniş farklılıklarının ve kendi deneyimlerinin etkili olduğunu ifade etmektedir. Ramírez (2005, akt. Oktaç, 2008) araştırmasında lineer denklem sistemleri konusu öğretiminde kullanılan örneklerin tek çözümlü sistemler üzerinde yoğunlaştığını ve öğrencilerin denklem sistemlerinin çözümünün olmaması durumunu anlamlandırmakta zorlandıklarını belirtmiştir. Lineer denklem sistemleri çözüm sürecinde karşılaşılan güçlükleri performansa göre değerlendiren Erbaş, Çetinkaya ve Ersoy (2009) düşük performans gösteren öğrencilerin yanlışlarının, daha çok yanlış kurallamalara dayalı, orta ve yüksek performans sergileyen öğrencilerin yanlışlarının ise daha çok aritmetik veya işlemsel olduğunu ifade etmişlerdir.

\section{Öz-yeterlik Algısı}

Sosyal psikolojinin temel kavramlarından biri olan öz-yeterlik algısı fen, matematik, yabancı dil, sosyal bilimler gibi çok sayıda farklı disiplinlerde kullanılmış ve üzerinde çalışılmış bir kavramdır. Bu kavramın Türkçeye adapte edilirken "yetkinlik beklentisi, öz-yeterlilik inancı ve öz-yeterlik algısı" gibi kullanımlarına rastlanmakta olup bu araştırmada öz-yeterliğin bilişsel yönüne odaklanıldığı için "öz-yeterlik algısı" benimsenmiş ve kullanılmıştır.

Öz-yeterlik algısı kavramı temelini Bandura tarafından geliştirilen sosyal bilişsel kuramdan alır (Stone, 1998). Bandura (1977) ilk olarak "bir kişinin istenilen sonuca ulaşmada kendi yeteneğine olan kişisel inancı" olarak tanımladığı öz-yeterlik algısı kavramını sonraları daha da genişletilerek "öz-yeterlik algısı, davranışların oluşmasında etkili bir niteliktir ve bireyin farklı durumlarla baş etme, belli bir performansı göstermek için gerekli etkinlikleri düzenleyip, başarılı olarak yapma kapasitesi hakkındaki algılayışı, inancı ve yargisı" olarak tanımlanmıştır (1986, s. 391; 1997, s. 3). Ford (1992) öz-yeterlik algısını, insanları, öğretmenler de dahil, güven içinde başarmak ve başardıklarını uygulamaya dökebilmek için motive eden kişisel yeteneklerin bir parçası olarak tanımlarken Pajares (1996) belirli bir görevi yerine getirmek için yeteneklerin duruma özel değerlendirilmesi olarak ifade etmiştir. Öz-yeterlik algısı bireyin davranış potansiyeline dair kendisini değerlendirebilmesi olarak da ifade edilebilir (Kardeş, 2010) yani bireyin var olan yeteneklerinden ziyade ne yapabileceğine dair inanç, alg1 ve yargılarıyla ilgilidir.

Bandura (1997, s. 10) bireylerin öz-yeterlik algılarının geçmiş deneyimler, dolaylı deneyimler, ikna süreci ve duyuşsal süreç olmak üzere dört faktörden kaynakladığını belirtmiştir. Geçmiş deneyimler, özyeterlik algısının en temel olarak belirleyen bireyin kişisel deneyimleridir (a.g.e.). Birey davranışlarını değerlendirme yetisiyle birlikte kendini tanır ve tutumunu buna göre geliştirir. Yani öz-yeterlik algısı gelişiminin yüksek olması başarıyı getirdiği gibi, başarı da öz-yeterlik algısını geliştirir. Sosyal bilişsel kuram her ne kadar geleneksellikten uzaklaşsa da temelinde model alarak öğrenme modeli yatmaktadır (Bandura, 1977). Kişinin öz-yeterlik algısını geçmiş deneyimlerine göre daha az etkiler Dolaylı deneyimler bireyin kendine model olarak belirlediği bir kimsenin başarı ya da başarısızlıklarını dikkate alarak kendinin de başarılı ya da başarısız olacağına dair algı geliştirmesi olarak açıklanabilir (a.g.e). Burada seçilen model birey, öz-yeterlik algısının gelişimi bakımından önem arz etmektedir. Bu kişinin akran grubunda olup olmaması, yetenek bakımından özdeş olup olmamaları kişinin öz-yeterlik algı gelişimini etkileyecektir. İkna süreci, bireyin başarabileceği ya da başaramayacağına dair teşvik, nasihat ve öğütlerden oluşur (Şahinkaya, 2008). Duyuşsal süreç, bireyin ruh haleti ile ilgilidir. Korku, stres, karamsarlık, yorgunluk gibi duygular bireyin öz-yeterlik algısının olumsuz etkileyeceği gibi huzurlu ve mutlu olması öz-yeterlik algısını pozitif yönde etkileyecektir.

Öz-yeterlik algısı ile yapılan çalışmalarda öz-yeterlik algısının ölçülmesi amaçlanmıştır. Ayrıca yapılan çalışmalar öz-yeterlik algısı ile kariyer seçimi, okul başarısı ve dâhilinde fen ve matematik başarısının ilişkisi, öğretmen öz-yeterlikleri üzerinde çalışmalar ve akademik öz-yeterlik ile motivasyon, performans ve başarı ilişkisi temaları altında toplanabilir. Matematik eğitimi alanında yapılan çalışmalarda ise öz-yeterliliğin genel anlamda duyuşsal boyutları dikkate alınarak ölçekler geliştirilmiş veya uyarlanmaya 
çalışılmış; bu kavramı ölçmek hedeflenmiştir (Ünay, 2012; Göloğlu-Demir, 2011; Dede, 2008; Özgen ve Bindak, 2008; Umay, 2001; Enochs, Smith ve Huinker, 2000). Ayrıca matematik öğretimine ve öğrenimine yönelik ölçeklerin yanı sıra konu bazında geometri, trigonometri, origami, istatistik, somut modeller kullanma gibi ölçme araçlarının geliştirilerek veya uyarlanarak öz-yeterlik algısının ölçülmesinin hedeflendiği birçok çalışma mevcuttur (Arslan, 2012; Saraç, 2012; Sevimli, 2010; Cantürk-Günhan ve Başer, 2007, Bakkaloğlu, 2007; Finney ve Schraw, 2003). Konuya özgü öz-yeterlik algisı ile ilgili olarak, bu tür ölçeklerin performans öngörüsüne yönelik yargıları daha iyi yordadığı düşünülmektedir (Finney ve Schraw, 2003). Baki, Kutluca ve Birgin (2008) matematik öğretmen adaylarının bilgisayar destekli eğitime ilişkin özyeterlik algıları ile temel bilgisayar dersi başarı düzeyleri arasında başarı düzeyi iyi olanlar lehine anlamlı bir fark olduğunu tespit etmişlerdir. İstatistik öz-yeterliği ile istatistik başarıları arasındaki ilişkiyi araştıran Sevimli (2010) pozitif yönde anlamlı bir ilişkinin varlığından bahsetmektedir. Altun (2005) öz-yeterlik algı puanlarının matematik başarısını açıklamada anlamlı birer yordayıcı olduğunu ifade etmektedir. Bu araştırmada ise matematiksel içerik olarak belirlenen lineer denklem sistemleri konusundaki performans ile öz-yeterlik algısı arasındaki ilişki incelenmiştir. Bu bağlamda araştırmanın odağını matematik öğretmen adaylarının lineer denklem sistemleri konusunda sergiledikleri performans ile öz-yeterlik algı düzeyleri arasındaki ilişkinin incelenmesi oluşturmaktadır. Bu bağlamda cevaplanmaya çalışılacak problemler ise şunlardır;

$\checkmark$ Matematik öğretmen adaylarının lineer denklem sistemleri konusunda sergiledikleri genel performans nasıldır?

$\checkmark$ Matematik öğretmen adaylarının lineer denklem sistemleri konusunda sergiledikleri performanslar testte yer alan alt boyutlara göre nasıl değişmektedir?

$\checkmark$ Matematik öğretmen adaylarının lineer denklem sistemleri konusunda sergiledikleri performanslar değişken ve denklem sayısının durumuna göre nasıl değişmektedir?

$\checkmark$ Matematik öğretmen adaylarının lineer denklem sistemleri öz-yeterlik algı düzeyleri nasıldır?

$\checkmark$ Matematik öğretmen adaylarının lineer denklem sistemleri konusunda sergiledikleri performanslar ile öz-yeterlik algı düzeyleri arasındaki ilişki (testte yer alan alt boyutlara ve değişken ve denklem sayısının durumuna göre) nasıldır?

\section{Yöntem}

Araştırmada matematik öğretmen adaylarının lineer denklem sistemleri konusundaki sergiledikleri performansları ve bu konudaki öz-yeterlik algıları gerçekçi ve bütüncül bir biçimde ortaya konulması amaçlandığından, araştırma nitel paradigma üzerine kurulmuştur. Nitekim nitel araştırmalar, algıların ve olayların doğal ortamda gerçekçi ve bütüncül bir biçimde ortaya konmasına yönelik bir süreç olarak tanımlanmaktadır (Yıldırım ve Şimşek, 2006, s. 39; Lodico, Spaulding ve Voegtle, 2006, s. 264).

\section{Araştırma Deseni}

Araştırmada matematik öğretmen adaylarının öz-yeterlik algı düzeyleri ve performansları matematiksel içerik bakımından lineer denklem sistemleri konusu bağlamında incelendiğinden, araştırma özel durum çalışmasıdır. Bu araştırma deseni, belirli bir olay, durum, bireyleri ya da grupları durumun gerçekleştiği yer içerisinde sınırlı bir sürede derinlemesine incelemeye olanak veren bir yöntemdir (Yin, 2003, s. 39).

\section{Çalışma Grubu}

Katılımcılar, olasılıklı olmayan örnekleme yöntemlerinden amaçlı örnekleme tekniği (Cohen, Manion ve Morrison, 2000, s. 104) ile 2009-2010 eğitim öğretim yılında, bir devlet üniversitesi eğitim fakültesi ilköğretim matematik eğitimi lisans programına kayıtlı 42 lineer cebir öğrencisi katılmıştır. Amaca yönelik örnekleme katılımcıların araştırma soruları kapsamındaki bilgi birikimleri ve özellikleri dikkate alınarak seçilmesidir (Lodico, Spaulding ve Voegtle, 2006).

\section{Veri Toplama Araçları}

Matematik öğretmen adaylarına lineer denklem sistemleri konusunda sergiledikleri performanslarını betimlemek için araştırmacılar tarafından hazırlanan Lineer Denklem Sistemleri Performans Testi (LiPT) 
uygulanmıştır. LiPT'de yer alan 13 sorudan 12 tanesi klasik yazılı ve 1 tanesi tahmin ve yoruma açık olmak üzere çoktan seçmeli olacak şekilde tasarlanmıştır. Testte yer alan soruların iki tanesi aşağıda betimlenmiştir.

Tablo 1. Lineer Denklem Sistemleri Performans Testi Örnek Soru ve Karakteristikleri

\begin{tabular}{|c|c|}
\hline Örnek Sorular & Soruların Karakteristiği \\
\hline $\begin{array}{l}\text { 6. } \quad x_{1}+4 x_{2}-6 x_{3}=7 \\
\quad 2 x_{1}+3 x_{2}-4 x_{3}=12 \\
\quad 4 x_{1}+6 x_{2}-8 x_{3}=24 \\
\text { Lineer denklem sisteminin Cramer kuralı ve elemanter } \\
\text { satır işlemleri ile çözünüz. Çözümü cebirsel olarak } \\
\text { yorumlayını. }\end{array}$ & $\begin{array}{ll}\text { - } & \text { Homojen olmayan lineer denklem sistemi } \\
\text { - } & 3 \times 3 \text { boyut } \\
\text { - } & \text { Cramer kuralı } \\
\text { - } & \text { Sonsuz çözüm } \\
\text { - } & \text { Cebirsel yorum }\end{array}$ \\
\hline 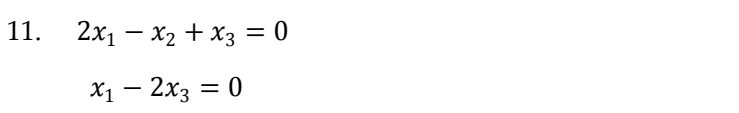 & $\begin{array}{l}\text { - Homojen lineer denklem sistemi } \\
\text { - } \quad 2 \times 3 \text { boyut } \\
\text { - } \quad \text { Elemanter Satır İşlemleri }\end{array}$ \\
\hline $\begin{array}{l}\text { Lineer denklem sisteminin katsayılar matrisinin rankını } \\
\text { hesaplayınız. Sistemi elemanter satır işlemleri yardımıyla } \\
\text { çözünüz. Çözümü cebirsel olarak yorumlayınız. }\end{array}$ & $\begin{array}{ll}\text { - } & \text { Sonsuz Çözüm } \\
\text { - } & \text { Cebirsel yorum }\end{array}$ \\
\hline
\end{tabular}

Öğretmen adaylarının testte aldıkları puan "doğru cevap=3, kısmi cevap=2, yanlış cevap=1, cevapsız=0" olmak üzere hesaplanmıştır böylelikle öğretmen adayının testten alabileceği maksimum puan 45 , minimum puan ise 0 şeklinde olacaktır. LIPT'nin deneme çalışması yapılmak üzere 47 kişilik 2. sınıf ortaöğretim matematik öğretmenliği bölümü öğrencilerine uygulanmıştır. Yapılan deneme çalışması testin ortalama uygulama süresinin belirlenmesi, karşılaşılan anlam ve mantık hatalarının giderilmesi, teste yer alan imla ve yazım hatalarının düzeltilmesi, benzer özellikler taşıyan grubun çözüm süreçleri ile gerçek uygulamalara yönelik fikir edinilmesi açısından önemlidir. Deneme çalışmalarında LIPT'nin tüm sınıf tarafından 50 dakikada tamamlandığı gözlendiğinden testin gerçek uygulama süresi olarak belirlenmiştir. LIPT'de yer alan maddeler düzenlenirken, ders kitapları, sınav soruları, okul notları ve konu ile ilgili yapılmış çalışmalar dikkate alınarak 78 soru belirlenmiştir. Belirlenen sorular arasında hedeflenen kazanımlar doğrultusunda 13 soru seçilmiştir. Seçilen sorular ile konu ile ilgili tüm alt başlıklara en az birer örnek verilmeye çalışılmış ve alınan beş uzman görüşü desteği ile kapsam ve görünüş geçerliğine sahip olduğu tespit edilmiştir.

LİPT'nin güvenirliğini belirlemek için bu testi cevaplayan öğrencilerden rastgele 5 öğrencinin cevap kâğıtları seçilmiş lineer cebir dersine vakıf olan üç uzman tarafından değerlendirilmiştir. Uzmanlar tarafından cevap kâğıtlarına verilen puanlar arasındaki ilişkiye Spearman korelasyon katsayısı ile bakılmış, hesaplanan değerlere (1. uzman puanı ile 2. uzman puanı arasındaki ilişki: r=0,77; 1 . uzman puanı ile 3. uzman puanı arasındaki ilişki: $r=0,85$; 2 . uzman puanı ile 3 . uzman puanı arasındaki ilişki: $r=0,82$ ) göre aradaki ilişkinin pozitif yönde anlamlı olduğu görülmüştür.

Matematik öğretmen adaylarının öz-yeterlik algı düzeylerini belirlemek için Lineer Denklem Sistemleri Öz-yeterlik Algısı Ölçeği (LIYAÖ) uygulanmıştır (Kardeş, 2010). Araştırmacılar tarafından geliştirilen bu ölçek 3 alt ölçekten oluşmaktadır. Buna sebep olan gerekçe ise değişken sayısı (n) ile denklem sayısının (m) birbirlerine göre durumlarından kaynaklanmaktadır. Değişken sayısının denklem sayısına eşit olduğu $(m=n)$ alt ölçekte 17, değişken sayısının denklem sayısından küçük olduğu $(\mathrm{m}<\mathrm{n})$ alt ölçekte 12 ve değişken sayısının denklem sayısından büyük olduğu $(\mathrm{m}>\mathrm{n})$ alt ölçekte 12 olmak üzere ölçekte toplamda 41 madde bulunmaktadır. LIYAÖ'nün geçerlik ve güvenirlik çalışmaları yapılmış olup, $m=n$ durumu için, Cronbach Alfa iç tutarlılık katsayısı 0.860; $\mathrm{m} \neq \mathrm{n}$ durumu için Cronbach Alfa iç tutarlılık katsayısı 0.835 olarak belirlenmiştir. Ölçeğin Cronbach Alfa iç tutarlılık katsayısı, $0.80 \leq \alpha<1.00$ aralığında ise ölçek yüksek derecede güvenilir olduğu ifade edilmektedir (Özdamar, 1999). Veri toplama sürecinde ise geliştirilen veri toplama araçlarının birbiri üzerindeki olumsuz etkilerini önlemek için ayrı zamanlarda öncelik ölçeğe verilecek şekilde uygulama yapılmıştır.

\section{Veri Analizi}

Lineer Denklem Sistemleri Performans Testinden elde edilen verilerin analizinde, matematik öğretmeni adaylarının cevapları doğru, kısmi ve yanlış cevap ile cevapsız olarak sınıflandırılmıştır. İşlem prosedürünün doğru ve sonucun doğru olduğu, kavram tanımının doğru yapıldığı cevaplar doğru cevap olarak; işlem prosedürünün doğru ve sonucun yanlış olduğu, işlem prosedürünün doğru ve 
sonuçlandırılamadığı, kavram tanımının doğru fakat eksik yapıldığı cevaplar kısmi cevap olarak; işlem prosedürünün yanlış olduğu ve sonucunun yanlış olduğu, işlem prosedürünün yanlış olduğu ve sonuçlandırılamadığı, kavram tanımının yanlış yapıldığı cevaplar yanlış cevap olarak; sorunun cevap olarak yeniden yazıldığı cevaplar ya da boş bırakılan sorular cevapsız olarak değerlendirilmiştir.

Matematik öğretmeni adaylarının lineer denklem sistemi performans düzeyini belirlerken yüksek, orta ve düşük düzey sınıflaması yapılmıştır. LIPT'den 31 ile 45 aralığında puan alan öğretmen adayları yüksek düzeyde performans (YDP), 16 ile 30 aralığında puan alan öğretmen adayları orta düzey performans (ODP) ve 0 ile 15 aralığında puan alan öğretmen adayları düşük düzeyde performans (DDP) sergiledikleri yönünde değerlendirilmiştir. Bu kriterler belirlenirken grubun normuna bağlı olmadığı için bağıl değerlendirme yapmak yerine mutlak değerlendirme yapmak tercih edilmiştir.

Matematik öğretmeni adaylarının öz-yeterlik algısı düzeylerini değerlendirmek için ölçekten aldıkları puanlarının aritmetik ortalamaları dikkate alınmıştır. Bu bağlamda, katılımcıların ölçekten alabilecekleri maksimum puan 5 iken minimum puan 1 olmaktadır. Bu puan sınırları arasında derecelendirme yapılarak Tablo 2'de yer alan kriterler oluşturulmuştur. LIPT'nin değerlendirilmesinde olduğu gibi grup normuna bağlı olmadığı için bağıl değerlendirme yapmak yerine mutlak değerlendirme yapmak tercih edilmiştir.

Tablo 2. LIYAÖ öz-yeterlik alg1 puanlarının genel ortalamaları

\begin{tabular}{ll}
\hline Aralıklar & Değerlendirme \\
\hline $1.00-1.49$ & Öz-yeterlik Algısı Çok Düşük (ÖYAÇD) \\
$1.50-2.49$ & Öz-yeterlik Algısı Düşük (ÖYAD) \\
$2.50-3.49$ & Öz-yeterlik Algısı Orta Düzeyde (ÖYAO) \\
$3.50-4.49$ & Öz-yeterlik Algısı Yüksek (ÖYAY) \\
$4.50-5.00$ & Öz-yeterlik Algısı Çok Yüksek (ÖYAÇY) \\
\hline
\end{tabular}

\section{Bulgular}

Araştırmada matematik öğretmen adaylarının lineer denklem sistemleri konusunda sergiledikleri performansları ile öz-yeterlik algı düzeyleri arasındaki ilişkinin incelenmesi amaçlanmıştır. Çalışmanın bu bölümü, araştırmanın amacı ve cevaplamaya çalıştığı sorular bağlamında lineer denklem sistemleri konusunda sergilenen performans, lineer denklem sistemleri öz-yeterlik algı düzeyleri ve lineer denklem sistemleri konusunda sergiledikleri performansları ile öz-yeterlik algı düzeyleri arasındaki ilişki başlıkları altında sunulmuştur.

\section{Lineer Denklem Sistemleri Konusunda Sergilenen Performans}

Matematik öğretmeni adaylarının lineer denklem sistemleri konusundaki performansları ile öz-yeterlik alg1 düzeyleri arasındaki ilişki incelenmeden önce bu konudaki performansları incelenmelidir. LİPT'ye verdikleri cevapların soru bazında performansları Tablo 3'te sunulmuştur.

Matematik öğretmeni adaylarının lineer denklem sistemleri konusundaki soru bazındaki performansları incelendiğinde 1., 6. ve 12. sorular hiç doğru cevaplanmamış olup aynı zamanda 1. ve 12. sorular en yüksek yüzde ile cevapsız bırakılmıştır. İlk soruda öğretmen adaylarından lineer denklem sistemlerini tanımlamaları beklenmektedir. 12. soruda öğretmen adaylarından 3 bilinmeyenli 3 denklemden oluşan denklem sistemini matrisin tersi yöntemiyle çözümlemeleri ve çözümü cebirsel-geometrik olarak yorumlamaları beklenmektedir. Altıncı soruda ise 2 bilinmeyenli 4 denklemden oluşan bir denklem sisteminin elemanter satır işlemleri ile çözümlenmesi ve çözümün geometrik yorumlanması beklenmektedir. Bu soru en çok yüzde ile kısmen cevaplanmıştır. 
Tablo3. Öğretmen adaylarının sergiledikleri performansları

\begin{tabular}{lcccc}
\hline \% & Doğru Cevap (DC) & Kismi Cevap (KC) & Yanlış Cevap (YC) & Cevapsız (CY) \\
\hline $\mathbf{1}$ & $\mathbf{0 . 0 0}$ & 16.67 & 42.86 & 40.48 \\
$\mathbf{2}$ & 26.19 & 14.29 & $\mathbf{5 4 . 7 6}$ & $\mathbf{4 . 7 6}$ \\
$\mathbf{3}$ & 23.81 & 52.38 & 19.05 & $\mathbf{4 . 7 6}$ \\
$\mathbf{4}$ & 35.71 & 45.24 & 7.14 & 11.90 \\
$\mathbf{5}$ & 33.33 & 52.38 & 7.14 & 7.14 \\
$\mathbf{6}$ & $\mathbf{0 . 0 0}$ & $\mathbf{5 9 . 5 2}$ & 21.43 & 19.05 \\
$\mathbf{7}$ & 57.14 & 19.05 & 16.67 & 7.14 \\
$\mathbf{8}$ & 11.90 & 47.62 & 4.76 & 35.71 \\
$\mathbf{9}$ & 7.14 & 40.48 & 16.67 & 35.71 \\
$\mathbf{1 0}$ & $\mathbf{6 9 . 0 5}$ & $\mathbf{0 . 0 0}$ & $\mathbf{0 . 0 0}$ & 30.95 \\
$\mathbf{1 1}$ & 23.81 & 42.86 & 9.52 & 23.81 \\
$\mathbf{1 2}$ & $\mathbf{0 . 0 0}$ & 52.38 & 7.14 & $\mathbf{4 0 . 4 8}$ \\
$\mathbf{1 3 . 1}$ & 30.95 & 0.00 & 42.86 & 26.19 \\
$\mathbf{1 3 . 2}$ & 28.57 & 0.00 & $\mathbf{4 7 . 6 2}$ & 23.81 \\
$\mathbf{1 3 . 3}$ & $\mathbf{5 9 . 5 2}$ & 0.00 & 9.52 & 30.95 \\
\hline
\end{tabular}

En çok doğru cevaplanan soru ise \% 69.05 yüzde ile 10. soru olmuştur. 10. soruda öğretmen adaylarından $2 \times 2$ boyutlu matrisin ek matrisinin bulunması istenmiştir. Bu sorudan alınan cevapların hepsinin doğru olması, kısmi ve yanlış cevabın olmaması dikkat çekmektedir. Bunu \% 59.52 yüzde ile 13.3. soru takip etmektedir. 13. sorunun niteliği gereği (çoktan seçmeli) doğru cevap, yanlış cevap ve cevapsız olmak üzere 3 kategoride değerlendirmesi yapılmıştır. En az yüzde ile boş bırakılan 2. soru en yüksek yüzde ile (\%54.76) yanlış yapılan soru olmuştur. Bu soruda, öğretmen adaylarından 3 bilinmeyenli 2 denklemden oluşan denklem sistemini $\mathrm{AX}=\mathrm{B}$ formunda yazmaları istenmiştir. Bu soruyu \% 47.62 yüzde ile yanlış cevaplanan 13.2. numaralı soru takip etmektedir. 13. numaralı sorularda öğretmen adaylarından geometrik temsil verilmiş bir denklem sisteminin cebirsel form örneğini seçmeleri beklenmiştir.

Matematik öğretmen adaylarının lineer denklem sistemleri konusundaki genel performans düzeyleri incelendiğinde ise adayların \%17'si YDP, \%76'sı ODP ve \%7'si DDP sergilemişlerdir. Adayların çoğunluğunun orta düzey performans sergilediği görülmektedir.

LIPT'ye verilen cevaplar testin alt boyutlarına göre analiz edildiğinde, ters matrisle çözüm bulmayı gerektiren sorular en yüksek yüzde ile doğru cevaplanmıştır $(\% 35,32)$. Geometrik yorumlama yapılması beklenen sorular ise en düşük yüzde ile doğru cevaplanmıştır (\% 3.97). Geometrik yorumlama yapılması beklenen sorular aynı zamanda en çok kısmi cevaplanan, en az yanlış cevaplanan ve en çok boş bırakılan sorular olmuştur. En çok yanlış yapılan sorular denklem sayısının değişken sayısından farklı olduğu $(m \neq n)$ satır işlemleri ile çözüm yapmayı içeren sorulardır. Değişken sayısının denklem sayısına eşit olduğu $(m=n)$ rank ile çözüm bulmayı içeren sorular en az boş bırakılan sorular olmuştur (Tablo 4.).

Tablo 4. LIPT'ye verilen cevapların testin alt boyutlarına göre analizi

\begin{tabular}{lcccc}
\hline \multicolumn{1}{c}{$(\mathbf{\%})$} & DC & KC & YC & CY \\
\hline Satır işlemleri ile çözme $(\mathbf{m \neq n})$ & 19.84 & 42.06 & $\mathbf{2 7 . 7 8}$ & 10.32 \\
Rank ile çözüm bulma $(\mathbf{m = n})$ & 23.81 & 52.38 & 19.05 & $\mathbf{4 . 7 6}$ \\
Determinantla çözüm bulma & 25.40 & 35.71 & 12.70 & 26.19 \\
Ters matrisle çözüm bulma & 35.32 & 28.97 & 15.87 & 19.84 \\
Cebirsel yorumlama & 26.59 & 24.21 & 21.83 & 27.38 \\
Geometrik yorumlama & $\mathbf{3 . 9 7}$ & $\mathbf{5 3 . 1 7}$ & $\mathbf{1 1 . 1 1}$ & $\mathbf{3 1 . 7 5}$ \\
\hline
\end{tabular}


Matematik öğretmeni adaylarının LIPT'ye verdikleri cevaplar denklem sistemlerinin boyutlarına göre analiz edildiğinde, denklem sayısının değişken sayısına eşit olduğu soruların eşit olmadığı sorulara göre doğru cevaplanma ve cevapsız bırakılma yüzdesi daha yüksek, kısmen ve yanlış cevaplanma yüzdesi daha düşüktür (Tablo 5.).

Tablo 5. LIPT'ye verilen cevapların denklem sistemlerinin boyutlarına göre analizi

\begin{tabular}{lrrr}
\hline \multicolumn{1}{c}{$(\%)$} & DC & KC & YC \\
\hline $\begin{array}{l}\text { Denklem sayısının değişken sayısına eşit olduğu durum } \\
(\mathbf{m}=\mathbf{n})\end{array}$ & 33.57 & 25.24 & 17.62 \\
\hline $\begin{array}{l}\text { Denklem sayısının değişken sayısına eşit olmadı̆̆ı durum } \\
(\mathbf{m} \neq \mathbf{n})\end{array}$ & 17.86 & 43.45 & 22.02 \\
\hline
\end{tabular}

\section{Lineer Denklem Sistemler Öz-yeterlik Algı Düzeyleri}

Matematik öğretmeni adaylarının lineer denklem sistemleri konusunda sergiledikleri performans ile öz-yeterlik algı düzeyleri arasındaki ilişki incelenmeden önce öz-yeterlik algı düzeyleri incelenmelidir. Öğretmen adaylarının öz-yeterlik algı düzeyleri ölçekte yer alan alt boyutlar ve alt ölçekler bağlamında bu başlık altında sunulmuştur (Tablo 6.).

Ölçeğin $\mathrm{m}<\mathrm{n}$ alt boyutunda, satır işlemleri ile çözüm bulma alt boyutunun ortalaması 3.72, standart sapması 0.86; cebirsel yorumlama alt boyutunun ortalaması 3.32, standart sapmas1 1.03; geometrik yorumlama alt boyutunun ortalaması 2.99 , standart sapması 0.87 hesaplanmıştır. $m=n$ durumunda; ters matrisle çözüm bulma alt boyutunun ortalaması 3.60, standart sapması 0.68; rankla çözüm bulma alt boyutunun ortalaması 3.81, standart sapması 0.96; determinantla çözüm bulma alt boyutunun ortalaması 3.21, standart sapması 0.72; cebirsel yorumlama alt boyutunun ortalaması 3.61, standart sapması 1.09; geometrik yorumlama alt boyutunun ise ortalaması 3.04, standart sapması 0.96 bulunmuştur. $\mathrm{m}>\mathrm{n}$ durumunda; satır işlemleri ile çözüm bulma alt boyutunun ortalaması 3.76, standart sapması 0.87; cebirsel yorumlama alt boyutunun ortalaması 3.57, standart sapması 0.97; geometrik yorumlama alt boyutunun ortalaması 3.23 standart sapması 0.72 olduğu tabloda görülmektedir.

Tablo 6. Lineer Denklem Sistemleri Öz-Yeterlik Ölçeği $(m<n, m=n, m>n)$ ve alt boyutlarının betimsel istatistiği

\begin{tabular}{|c|c|c|c|c|c|}
\hline Ölçek & Alt Boyutlar & $\mathbf{N}$ & $X$ & ss & $\mathrm{SH}$ \\
\hline \multirow{3}{*}{$\mathbf{m}<\mathbf{n}$} & Satır işlemleri ile çözüm bulma & 42 & 3.72 & 0.86 & 0.18 \\
\hline & Cebirsel yorumlama & 42 & 3.32 & 1.03 & 0.21 \\
\hline & Geometrik yorumlama & 42 & 2.99 & 0.87 & 0.18 \\
\hline \multirow{5}{*}{$\mathbf{m}=\mathbf{n}$} & Ters matrisle çözüm bulma & 42 & 3.60 & 0.68 & 0.14 \\
\hline & Rankla çözüm bulma & 42 & 3.81 & 0.96 & 0.19 \\
\hline & Determinantla çözüm bulma & 42 & 3.21 & 0.72 & 0.15 \\
\hline & Cebirsel yorumlama & 42 & 3.61 & 1.09 & 0.22 \\
\hline & Geometrik yorumlama & 42 & 3.04 & 0.96 & 0.20 \\
\hline \multirow{3}{*}{$\mathbf{m}>\mathbf{n}$} & Satır işlemleri ile çözüm bulma & 42 & 3.76 & 0.87 & 0.18 \\
\hline & Cebirsel yorumlama & 42 & 3.57 & 0.97 & 0.15 \\
\hline & Geometrik yorumlama & 42 & 3.23 & 0.72 & 0.16 \\
\hline
\end{tabular}


Matematik öğretmen adaylarının genel öz-yeterlik alg1 düzeyleri incelendiğinde, adayların \%59,52'sinin ÖYAY, \%33,33'ünün ÖYAO, \%9,52'sinin ÖYAD'tür. ÖYAÇY ve ÖYAÇD olan öğretmen aday1 bulunmamaktadır. Bu sınıflarda bulunan öğretmen adayı olmadığı için ÖYAÇY ile ÖYAY ve ÖYAÇD ile ÖYAD sınıflarının birleştirilmesi araştırmacılar tarafından uygun görülmüş olup öz-yeterlik algı düzeyleri yüksek, orta ve düşük olmak üzere üç sınıfta ele alınmıştır. Matematik öğretmeni adaylarının yarısından fazlasının genel öz-yeterlik algısı düzeyleri yüksek çıkmıştır.

\section{Lineer Denklem Sistemleri Konusundaki Performans ile Öz-Yeterlik Algısı Arasındaki İlişkinin İncelenmesi}

Araştırmanın temelde cevap aradığı sorulardan biri olan matematik öğretmen adaylarının lineer denklem sistemleri performanslarının öz-yeterlik alg1sı bağlamında incelenmesi problemi, parametrik olmayan durumlar üzerinde gerçekleştiğinden, Spearman korelasyon ile aradaki ilişkinin belirlenmesi gereği duyulmuştur. Bu bağlamda, lineer denklem sistemleri performanslarına göre üç ve öz-yeterlik algısına göre üç gruba ayrılan katılımcıların performansları ile öz-yeterlik algı düzeyleri arasında pozitif yönde orta düzeyde anlamlı ilişki bulunmaktadır ( $r=0.46 ; \mathrm{p}<.05)$.

Lineer denklem sistemleri performansları ile öz-yeterlik algısı arasındaki ilişki alt boyutlar bağlamında değerlendirilecek olursa Tablo 4 ve Tablo 6' daki veriler dikkate alınmalıdır. Satır işlemleri ile çözüm bulma $(m \neq n)$ alt boyutunda öğretmen adaylarının yaklaşık \%20'si doğru cevap, yaklaşık \%40'1 kısmi cevap, yaklaşık \%30'u ise yanlış cevap vermiştir. Bu durumda öğretmen adaylarının lineer denklem sistemleri performanslarının orta düzeyde olduğu söylenebilir. Bu alt boyutta öğretmen adaylarının öz-yeterlik algıları ortalaması 3.74 olarak hesaplanmıştır. Bu değer ise öğretmen adaylarının satır işlemleri yapma $(m \neq n)$ alt boyutunda kendilerini yeterli gördükleri anlamına gelmektedir. Satır işlemleri yapma $(m \neq n)$ alt boyutunda kendilerini yeterli gören matematik öğretmeni adayları orta düzeyde performans sergilemişlerdir.

Rankla çözüm bulma $(m=n)$ alt boyutunda öğretmen adaylarının yarısı kısmi cevap verirken, çeyreği ise doğru cevap vermiştir. Bu durum katılımcıların bu alt boyutta yüksek düzeyde performans gösterdikleri şeklinde değerlendirilebilir. Bu alt boyutun öz-yeterlik algı ortalamasının 3.81 olması kendilerini yeterli gördükleri anlamına gelmektedir. Rankla çözüm bulma $(m=n)$ alt boyutunda kendilerini yeterli gören matematik öğretmeni adayları yüksek düzeyde performans sergilemişlerdir. Katılımcıların bu alt boyutta öz-yeterlik algıları ile performanslarının paralellik gösterdiği söylenebilir.

Determinantla çözüm bulma alt boyutunda, katılımcıların çeyreği soruları cevapsız bırakmıştır. Alınan cevaplar incelendiğinde katılımcıların çeyreği doğru cevap vermiştir. Bu durum öğretmen adaylarının orta düzeyde performansa sahip olduklarını göstermektedir. Katılımcıların bu alt boyutta öz-yeterlik algı ortalamalarının 3.21 olması kendilerini orta seviyede yeterli gördükleri anlamına gelmektedir. Determinantla çözüm bulma alt boyutunda kendilerini orta düzeyde yeterli gören matematik öğretmeni adayları orta düzeyde performans sergilemişlerdir. Katılımcıların bu alt boyutta öz-yeterlik algıları ile performanslarının paralellik gösterdiği söylenebilir.

Ters matrisle çözüm bulma alt boyutu, performans testinde öğretmen adaylarının en çok doğru cevap verdikleri alt boyuttur. Bu bakımdan katılımcıların performanslarının iyi olduğu şeklinde değerlendirme yapılabilir. Bu boyuta ait öz-yeterlik ortalamasının 3.60 olması katılımcıların kendilerini yeterli gördükleri anlamına gelmektedir. Ters matrisle çözüm bulma alt boyutunda kendilerini yeterli gören matematik öğretmeni adayları yüksek düzeyde performans sergilemişlerdir. Katılımcıların bu alt boyutta öz-yeterlik algıları ile performanslarının paralellik gösterdiği söylenebilir.

Cebirsel yorumlama alt boyutunda öğretmen adaylarının çeyreği doğru cevap ve çeyreği kısmi cevap vermiştir. Bu durum öğretmen adaylarının bu alt boyutta orta düzeyde olduklarını göstermektedir. Bu boyutun öz-yeterlik algısı ortalamasının 3.50 olması öğretmen adaylarını kendilerini yeterli gördükleri anlamına gelmektedir. Cebirsel yorumlama alt boyutunda kendilerini yeterli gören matematik öğretmeni adayları orta düzeyde performans sergilemişlerdir.

Geometrik yorumlama alt boyutu, öğretmen adaylarının en düşük performans gösterdikleri boyuttur. Bu boyut katılımcıların en az doğru cevapladıkları boyut olma özelliğine sahiptir. Bu bağlamda öğretmen 
adaylarının bu boyutta düşük düzeyde performansa sahip oldukları söylenebilir. Öz-yeterlik algıları ortalamaları ise bu boyutta 3.08'dir. Bu durumda öğretmen adayları bu alt bu alt boyutta orta düzeyde yeterli gördükleri anlamına gelmektedir. Geometrik yorumlama alt boyutunda kendilerini orta düzeyde yeterli gören matematik öğretmeni adaylarının performansları düşük düzeydedir.

Tablo 7. Lineer denklem sistemleri performansları ile öz-yeterlik algıları arasındaki ilişkinin incelenmesi

\begin{tabular}{cccc}
\hline$\%$ & YDP & ODP & DDP \\
\hline ÖYAY & 20 & 36 & 4 \\
ÖYAO & 4 & 24 & 4 \\
ÖYAD & 0 & 4 & 4 \\
\hline
\end{tabular}

Ayrıca öğretmen adaylarının lineer denklem sistemleri konusunda sergiledikleri performansları ile özyeterlik algıları arasındaki ilişkinin bu değişkenlerdeki seviyelerine göre incelenmesi de önemlidir. Matematik öğretmeni adaylarının \%20'si yüksek düzeyde performans sergilerken yüksek düzeyde yeterliğe sahiptir, \% 24'ü orta düzeyde performans sergilerken orta düzeyde yeterliğe sahiptir, \%4'ü düşük düzeyde performans sergilerken düşük düzeyde yeterliğe sahiptir (Tablo 7.).

\section{Tartışma}

Matematik öğretmen adaylarının lineer denklem sistemleri öz-yeterlik algı düzeyleri yüksek çıkmıştır. Yapılan araştırmalar incelendiğinde matematik, geometri, istatistik, bilgisayar destekli matematik eğitimi, matematik eğitiminde somut materyal kullanımı, matematik öğretimi konularına dayalı olarak yapılan incelemelerde yüksek düzeyde öz-yeterlik algısı karşılaşılan bir durumdur (Sevimli, 2010; Dede, 2008; Baki, Kutluca ve Birgin, 2008; Yürekli, 2008; Bakkaloğlu, 2007; Işıksal ve Çakıroğlu, 2006; Umay, 2001). Öz-yeterlik algısını ölçmeyi amaçlayan araştırmalarda kullanılan ölçeklerin çoğunda bilişsel boyut bulunması ile birlikte duyuşsal ve davranışsal boyutlara da yer verilmektedir (Enochs, Smith ve Huinker, 2000). Lineer Denklem Sistemleri Öz-yeterlik Algısı Ölçeği matematik öğretmen adaylarının problem çözme sürecindeki yeterliklerine odaklandığından sadece bilişsel boyut dikkate alınarak hazırlanmış ve geliştirilmiştir. Boyutlar dikkate alındığında sonuçların paralellik göstermesi ölçeğin tek bir boyut ölçüyor olmasına rağmen geçerliğine işaret ettiği söylenebilir.

Öğretmen adaylarının mezun olduğu ortaöğretim matematik öğretim programında yer almasına, üniversite sinavlarında kendisine yer bulmasına ve lisans programlarında lineer cebir dersinde ele alınmasına rağmen lineer denklem sistemleri konusunda sergiledikleri performansın çok yüksek düzeyde olmaması birkaç sebebe dayandırılabilir. Öncelikle matematiğin diğer kavramlarında sembolik temsil olarak farklılık göstermesi, bir kural yığını olması ve sadece sorularla değil diğer matematik konuları ve bağlamlarında karşılaşılarak pekiştireç olayının gerçekleşmemesi sayılabilir. Geçerliği ve güvenirliği sağlanan ölçekte yer alan maddeler öğretmen adaylarının alışkın olduğu soru tipleri olduğu düşünüldügüünde performans düşüklüğünün işlem hatalarından da kaynaklandığı düşünülebilir.

Öğretmen adaylarının lineer denklem sistemleri konusunda sergiledikleri performansları alt boyutlarıyla ele alınacak olursa, öğretmen adaylarının elemanter satır işlemleri ile çözüme ulaşmaları beklenen sorularda kısmi cevap oranın doğru cevap oranına göre az olmuş olması, ayrıca bu boyutlarda en çok yanlışın yapılmış olması onların süreçte bu soruları cevaplamaya çalıştıkları fakat güçlük çektikleri anlamına gelebilir. Bunun da onların kuralı hatırlayamamaları/ yanlış kullanmaları ya da işlem hatasından kaynaklandığı söylenebilir.

Denklem sistemlerinin boyutlarına göre değerlendirme yapıldı̆̆ı takdirde, katılımcıların değişken sayısının denklem sayısına eşit olduğu durumda farklı olduğu duruma göre daha iyi performans sergilemiş olmaları öğretmen adaylarının kavramları içselleştirmesi ve ilişkilendirmesi yerine işlemsel yani kurallı anlamanın (Skemp, 1976) baskın olduğunun göstergesi olabilir. Diğer bir deyişle, işlemsel anlamaya sahip olan öğretmen adayları kendilerine sunulan kural listelerine yenilerini eklemiş olabilir (Harel ve Tall, 1989). $\mathrm{Bu}$ durum lineer denklem sistemleri başarısı için ön koşul olduğu düşünülen zihinlerindeki şemaların (Trigueros, Oktaç ve Manzanero, 2007) oluşumu ile ilgili problem olduğu düşünülebilir. Çünkü yeni kurallar 
yeni ilişkileri gerektirir. İyi oluşturulmadığı takdirde var olan bir kavramın imge ilişkilerini deforme edebilir.

Matematik öğretmen adaylarının lineer denklem sistemleri konusunda sergiledikleri performanslarının öz-yeterlik algı düzeyleri bağlamında değerlendirildiğinde, lineer denklem sistemleri konusunda sergilenen performansları ile öz-yeterlik algı düzeyleri arasında pozitif yönde orta düzeyde anlamlı ilişkinin varlığı özyeterlik algısının performansı etkilediğinin bir sonucu olduğu düşünülmektedir (Selçuk, Çalışkan ve Erol, 2008). Öğretmen adaylarının performanslarının öz-yeterlik algılarına göre düşük çıkmasında bireysel faktörlerle birlikte öğretimin niteliği de büyük rol oynamaktadır (Demiroğlu, 2013). Öğretmen adaylarının konuyla ilgili kuralları ve kavramları bildiklerinde soruları çözebilme inançları buna sebep olabilir (Yılmaz, 2007). Buna ek olarak öğretmenlerin derste sunduklarından ve takip edilen kitaptakilerden farklı tarzda soru sorması buna sebep olabilir. Ayrıca, öğretmen adaylarının büyük çoğunluğunun orta düzeyde performans göstermelerine, öğretimde kavramların anlamlandırılmasında ziyade işlem ve prosedürlere önem verilmesi aynı şekilde ölçme ve değerlendirmede de işlem ve prosedüre dayalı tekniklerin kullanılmasının (Aydın ve Delice, 2008) yol açtığı söylenebilir, çünkü öğretmen adayı kavram veya işlem boyutunda ilişkilendirmeleri göz ardı ediyor olabilir.

\section{Sonuç}

Matematik öğretmen adaylarının lineer denklem sistemleri öz-yeterlik algıları denklem ve değişken sayısının birbirlerinin durumlarına göre değerlendirildiğinde, öğretmen adayları en çok kendilerini denklem sayısının (m) değişken sayısından (n) büyük olduğunda yeterli görmektedir. Bunu denklem ve değişken sayısının birbirine eşit olma durumu takip etmektedir. Ayrıca öz-yeterlik algısı çok yüksek ve çok düşük öğretmen adayları bulunmamaktadır.

Matematik öğretmen adaylarının lineer denklem sistemleri konusunda sergiledikleri performansları incelendiğinde, öğretmen adaylarının sergiledikleri performanslarının genel ortalaması orta düzeyde çıkmıştır. Öğretmen adaylarının azınlığı yüksek ve düşük performansa sahiptir. Katılımcılar en çok ters matrisle çözme alt boyutunda iyi performans göstermişlerdir. Rank ile çözüm bulma ve satır işlemleri ile çözme alt boyutlarını yüksek oranla doğru cevaplamamış olmalarına rağmen kısmi cevaplama oranları yüksektir. Ayrıca öğretmen adayları en çok yanlışları elemanter satır işlemleri ile çözümleme boyutunda yapmışlardır. En çok yanıtsız bırakılan boyut ise geometrik yorumlama boyutu olmuştur. Denklem sistemlerinin boyutlarına göre değerlendirme yapılacak olursa katılımcılar değişken sayısının denklem sayısına eşit olduğu durumda farklı olduğu duruma göre daha iyi performans sergilemişlerdir.

Matematik öğretmen adaylarının lineer denklem sistemleri konusunda sergiledikleri performanslarının öz-yeterlik algı düzeyleri bağlamında değerlendirildiğinde, performansları ile öz-yeterlik algısı arasında pozitif yönde orta düzeyde anlamlı ilişki vardır ve öz-yeterlik algısı ile lineer denklem sistemleri performansı ilişkilidir. Lineer denklem sistemleri performansları ile öz-yeterlik algısı arasındaki ilişki alt boyutlar bağlamında sonuçları değerlendirilirse rankla çözüm bulma, determinantla çözüm bulma ve ters matrisle çözüm bulma alt boyutlarında katılımcıların performansları ile öz-yeterlik algıları örtüşmektedir. Fakat satır işlemleri çözüm bulma, cebirsel yorumlama ve geometrik yorumlama alt boyutlarında ise öğretmen adaylarının öz-yeterlik algıları yüksek olmasına rağmen lineer denklem sistemleri performansları orta düzeydedir. Ayrıca öğretmen adaylarının yarıya yakını yüksek seviyede öz-yeterlik algısına sahipken orta düzeyde performans sergilemişlerdir. Öğretmen adaylarının çeyreği öz-yeterlik algısı ve sergiledikleri performans orta düzeydedir. Yüksek düzeyde performans sergileyen öz-yeterlik algısı düşük olan öğretmen adayları yokken düşük düzeyde performans sergileyen öz-yeterlik algısı yüksek olan öğretmek adayları azınlıktadır.

\section{Öneri}

Lineer denklem sistemleri konusu, öğrencilerin ortaokuldan itibaren aşina olduğu bir konudur. Bu konunun temelinin atıldığı ve birçok problemin çözümünde kullanılan yerine koyma ve yok etme yönteminin sadece işlemsel sürecinin değil, kavramsal olarak öğretilmesi ve günlük hayatla ilişkilendirilmesi öğretimin diğer kademeleri açısından faydalı olacağı ve performansı arttıracağı düşünülmektedir. Ayrıca ortaöğretim müfredatında bu konu son döneme rast geldiği için işlenişine özen 
gösterilmemektedir. Bu durum özellikle üniversitelerin fen ve matematik alanları ağırlıklı bölümlerinde okuyacak öğrencilerin matematiğin soyut yapısı ile ilgili güçlük çekmesine sebep olacağına inanılmaktadır.

Bu çalışma, var olan durumu ortaya koymaya yönelik hazırlandığından dolayı, herhangi bir yazılım ya da öğretim materyalinin etkisine bakılmamıştır. Bu bağlamda, sınıf ortamının teknoloji yardımıyla yeniden düzenlenmesi ve zenginleştirilmesinin, kavram tanımı/ kavram imgesini zenginleştireceği, böylelikle farklı temsillerin kullanılabileceği ortamlar oluşturabileceği ve bu ortamların öğretmen adaylarının performanslarını arttıracağı düşünülmektedir.

\section{Kaynakça}

Altun, S. (2005). Öğrencilerin öz düzenlemeye dayalı öğrenme stratejilerinin ve öz yeterlik algularının öğrenme stilleri ve cinsiyete göre matematik başarısını yordama gücü. Yayınlanmamış Doktora Tezi. Yıldız Teknik Üniversitesi, Sosyal Bilimler Enstitüsü, İstanbul.

Arslan, O. (2012). Investigating beliefs and perceived self-efficacy beliefs of prospective elementary mathematics teachers towards using origami in mathematics education. Yayımlanmamış yüksek lisans tezi. Orta Doğu Teknik Üniversitesi, Sosyal Bilimler Enstitüsü, Ankara.

Aydın, E. ve Delice, A. (2008). Ölçme ve değerlendirmeye kavram yanılgıları perspektifinden bir bakış M.F. Özmantar, E. Bingölbali ve H. Akkoç (Ed). Matematiksel Kavram Yanılgıları ve Çözüm Önerileri. Ankara: PegemA.

Baki, A., Kutluca, T. ve Birgin, O. (2008). Matematik Öğretmeni Adaylarının Bilgisayar Destekli Eğitime Yönelik Öz-yeterlik Algılarının İncelenmesi. 8. International Education Technology Conference, Anadolu Üniversitesi, Eskişehir.

Bakkaloğlu, E. (2007). Preservice elementary mathematics teachers' efficacy beliefs about using manipulatives in teaching mathematics. Yayınlanmamış Yüksek Lisans Tezi, Orta Doğu Teknik Üniversitesi, Fen Bilimleri Enstitüsü, Ankara.

Bandura, A. (1977). Self- efficacy: Toward a unifying theory of behavioral change. Psychological Rewiew, 84, 191 215.

Bandura, A. (1986). Social Foundations of Thoughtand Action: A Social Cognitive Theory. Englewood Cliffs, NJ: Prentice -Hall.

Bandura, A. (1997). Self-efficacy: The Exercise of Control. New York: W.H. Freemanand Company.

Cantürk-Günhan, B. ve Başer, N. (2007). Geometriye Yönelik Öz-yeterlik Ölçeğinin Geliştirilmesi. Hacettepe Üniversitesi Ĕ̆itim Fakültesi Dergisi, 33, 68-76.

Carlson, D. (1993). The Linear Algebra Curriculum Study Group Recommendations for the First Course in LinearAlgebra, College Mathematics Journal, 12 (1) 41-46.

Cohen, L.,Manion, L. ve Morrison, K. (2000). Research Methods In Education, (5th Edition). London: Routledge.

Cutz, B. (2005). Un esudioacerca de lasconcepciones de estudiantes de licenciaturasobrelossistemas de ecuaciones y su solición. Yüksek Lisans tezi. Cinvestav-IPN, Meksika.

Dede, Y. (2008). Matematik Öğretmenlerinin Öğretimlerine Yönelik Öz-Yeterlik İnançları. Türk Eğitim Bilimleri Dergisi, 6(4), 741-757.

Demiroğlu, D. (2013). Matematik ve Fizik Alan ve Alan Eğitimi Lisans Lisansüstü Programlarında Ölçme ve Değerlendirme Yaklaşımları ve Ders İçi Uygulamalar. Yayımlanmamış Yüksek Lisans Tezi, Marmara Üniversitesi, Eğitim Bilimleri Enstitüsü, İstanbul.

Enochs, L., G., Smith, P., L., and Huinker, D. (2000). Establishing Factorial Validity of the Mathematics Teaching Efficacy Beliefs Instrument. School Science and Mathematics, 100(4), 194-202.

Erbaş, A. K., Çetinkaya, B. ve Ersoy, Y. (2009). Öğrencilerin Basit Doğrusal Denklemlerin Çözümünde Karşılaştıkları Güçlükler ve Kavram Yanılgıları. Eğitim ve Bilim Dergisi, 34 (153). 
Finney, S. J ve Schraw G. (2003). Self-efficacy beliefs in college statistics courses. Contemporary Educational Psychology, 28, 161-186.

Ford, M. E. (1992). Motivating Humans: Goals, Emotions and Personal Agency Beliefs. Newbury Park, CA: Sage Publications, Inc.

Göloğlu-Demir, C. (2011). İlköğretim Matematik Öğretmenliği Programında Öğrenim Gören Öğrencilerin Matematik Öğretimine Yönelik Öz-yeterlik İnançlarını ve Tutumlarının İncelenmesi. Yayınlanmamış Yüksek Lisans Tezi. Gazi Üniversitesi, Eğitim Bilimleri Enstitüsü, Ankara.

Häggström, J. (2006). Thesametopic - Differentopportunitiestolearn. The fifth mathematics education research seminar. Malmö, İsveç.

Harel, G. Ve Tall, D. (1989). The general, tehabstractandthegeneric in advanced mathematics. For the Learning of Mathematics, 11(1), 38-42.

Işıksal, M. ve Çakıroğlu, E. (2006). İlköğretim Matematik Öğretmen Adaylarının Matematiğe ve Matematik Öğretimine Yönelik Yeterlik Algıları. Hacettepe Üniversitesi Ĕ̆itim Fakültesi Dergisi, 31, 74-84.

Kardeş, D. (2010). Matematik Öğretmen Adaylarının Lineer Denklem Sistemleri Çözüm Süreçlerinin Öz-Yeterlilik Algısı ve Çoklu Temsil Bağlamında İncelenmesi. Yayımlanmamış Yüksek Lisans Tezi, Marmara Üniversitesi, Eğitim Bilimleri Enstitüsü, İstanbul.

Lodico, M.G., Spualding, D.T. ve Voegtle, K.H. (2006). Methods in Educational Research: From Theory to Practice. San Francisco: Jossey-Bass Wiley.

Oktaç, A. (2008). Ortä̈ğretim Düzeyinde Lineer Cebir ile İlgili Kavram Yanılgıları. Özmantar vd. (Ed.) Matematiksel Kavram Yanılgıları ve Çözüm Önerileri (s. 329-360). Ankara: Pegema Yayıncılık.

Özdamar, K. (1999). Paket Programları ile İstatistiksel Veri Analizi, Kaan Kitabevi, Eskişehir.

Özgen, K. ve Bindak, R. (2008). Matematik okur-yazarlık ölçeğinin geliştirilmesi. Kastamonu Eğitim Dergisi, 16(2), 517-528.

Pajares, F. (1996). Self- Efficacy Beliefs in Academic Settings. Rewiev of Educational Research, 66(4), 543-578.

Ramírez, M. (2005). Dificultadesquepresentanlosestudiantes en lossistemas deecuacioneslineales en losmodosgeométrico y analítico. Lisans tezi. Universidad Autónoma de Guerrero, Meksika.

Saraç, A. (2012). The relation of teacher efficacy to students' trigonometry self-efficacy and trigonometry achievement. Yayımlanmamış yüksek lisans tezi. Boğaziçi Üniversitesi, Fen Bilimleri Enstitüsü, İstanbul.

Selçuk, G. S., Çalışkan, S. ve Erol, M. (2008). Physics self-efficacy beliefs of student teachers': The relationships with gender and achievement perception, Balkan Physics Letters (Special Issue: Turkish Physical Society 24th International Physics Congress), p. 648-651.

Sevimli, N. E. (2010). Matematik öğretmen adaylarının istatistik dersi konularındaki kavram yanılgıları; istatistik dersine yönelik öz yeterlilik inançları ve tutumlarının incelenmesi. Yayınlanmamış Yüksek Lisans Tezi. Marmara Üniversitesi, Eğitim Bilimleri Enstitüsü, İstanbul.

Skemp, R. R. (1976). Relational understanding and instrumental understanding. Mathematics Teaching, 77, 20-26.

Stone, D. (1998). Social Cognitive Theory. Güney Florida Üniversitesi.

Şahinkaya, N. (2008). Türkiye - Finlandiya Sınıf Öğretmenliği Matematik Öğretimi Programları, Simıf Öğretmeni Adayları ile Öğretmenlerin Öz Yetkinlik ve Öğrenme-Öğretme Süreçleri Açısından Karşılaştırılması. Yayınlanmamış Doktora Tezi, Gazi Üniversitesi, Eğitim Bilimleri Enstitüsü, Ankara.

Trigueros, M.,Oktaç, A. ve Manzanero, L. (2007). Understanding of System of Equations in Linear Algebra Working Group 14. CERME 5, 2007.

Umay, A. (2001). İlköğretim matematik öğretmenliği programının matematiğe karşı özyeterlik algısına etkisi. Journal of Qafqaz University,8. 
Ünay, E. (2012). Bireysel destek eğitiminin kaynaştırma öğrencilerinin matematik başarıları ve özyeterlilik algıları üzerindeki etkililiği. Yayımlanmamış yüksek lisans tezi. Dokuz Eylül Üniversitesi, Eğitim Bilimleri Enstitüsü, İzmir.

Yıldırım, A. ve Şimşek, H. (2006). Sosyal Bilimlerde Nitel Araştırma Yöntemleri (6. Baskı). Ankara: Seçkin Yayıncılık.

Yılmaz, K. (2007). Öğrencilerin epistemolojik ve matematik problemi çz̈zümlerine yönelik inançlarının problem çözme sürecine etkisinin araştırılması. Yayınlanmamış Yüksek Lisans Tezi. Marmara Üniversitesi, Eğitim Bilimleri Enstitüsü, İstanbul.

Yin, R. K. (2003). Case Study Research Design and Methods. Third Edition. Thousand Oaks, CA: Sage.

Yürekli, Ü. B. (2008). Sını Öğretmeni Adaylarının Matematiğe Yönelik Öz-yeterlilik Algıları ve Tutumları Arasındaki İlişki. Yayınlanmamış Yüksek Lisans Tezi. Pamukkale Üniversitesi, Sosyal Bilimler Enstitüsü, Denizli. 